\title{
ARTICLE OPEN \\ A retrospective study of the impact of a telephone alert service (Healthy Outlook) on hospital admissions for patients with chronic obstructive pulmonary disease
}

\author{
Christophe Sarran ${ }^{1}$, David Halpin ${ }^{2}$, Mark L Levy ${ }^{3,5}$, Samantha Prigmore ${ }^{4}$ and Patrick Sachon ${ }^{1}$
}

BACKGROUND: Healthy Outlook is a service delivered by the UK Met Office directly to patients with chronic obstructive pulmonary disease (COPD) that has been in place since 2006. Its objective is to reduce the severity and length of COPD exacerbations, hence improving the quality of life and life expectancy.

AIMS: To assess the effect of the Healthy Outlook service on hospital admission rates of all general practitioners that have used the service.

METHODS: Control practices were selected for each of the 661 participating practices. The number of hospital admissions for each practice was extracted from the Hospital Episode Statistics database. The differences in admission rates per practice between the first year of use of the Healthy Outlook service and the previous year were compared by paired $t$-test analyses.

RESULTS: For admissions with a primary diagnosis of COPD, the difference between participating and control practices was - $0.8 \%$ (95\% confidence interval $(\mathrm{Cl})=-1.8$ to $0.2 \% ; P=0.13)$. For admissions with a primary or co-morbid diagnosis of COPD, the difference was $-2.3 \%(95 \% \mathrm{Cl}=-4.2$ to $-0.4 \% ; P=0.02)$.

CONCLUSIONS: Participation in the Healthy Outlook service reduces hospital admission rates for patients coded on discharge with COPD (including co-morbid).

npj Primary Care Respiratory Medicine (2014) 24, 14080; doi:10.1038/npjpcrm.2014.80; published online 23 October 2014

\section{INTRODUCTION}

Chronic obstructive pulmonary disease (COPD) is a frequent cause of hospital admission and a significant burden to health services worldwide. It is predicted that it will be the third likely leading cause of death globally by $2020 .^{1,2}$ In England, it is estimated that COPD affects 3 million people and accounts for 1.4 million general practice consultations, one million inpatient bed days and over 23,000 deaths each year. ${ }^{3}$ COPD is the second most common cause of emergency admission to hospital in England and one of the most costly inpatient conditions treated by the NHS. ${ }^{3}$ It results in an indirect cost to the economy of $£ 3.8$ billion. COPD exacerbations, in particular those requiring hospitalisation, are associated with significant mortality and morbidity. Patient recovery is slow and is a major burden for health services. ${ }^{4-6}$

Several studies have shown an association between symptoms of COPD and meteorological factors. Coughing has been associated with minimum temperature, humidity and wind speed, as well as with shortness of breath with minimum temperature. ${ }^{7}$ Exhaled nitric oxide levels, an indicator of airway inflammation, have been associated with lower temperatures. ${ }^{8}$ In Bavaria, the daily number of ambulatory care visits was associated with temperature, atmospheric pressure and solar radiation, with further associations with humidity and wind speed in North Bavaria. ${ }^{9}$ Koskela et al. ${ }^{10}$ have measured in the laboratory the effect of low temperatures on respiratory health, including bronchoconstriction present in COPD patients undergoing hyperventilation with cold air. A recent analysis by Hondula et al. ${ }^{11}$ found that, although the association between respiratory health and meteorological variables are complex, models using meteorological parameters may be sufficiently predictive to be used as an early warning system. Indeed, using the UK Met Office's Healthy Outlook service, the predictive ability of weather parameters for COPD exacerbations has been demonstrated. ${ }^{12}$

Some telemedicine interventions ${ }^{13}$ and disease management models ${ }^{14}$ have reported reductions in hospital admission rates and significant improvements in outcomes of care, ${ }^{15-17}$ whereas others have shown no benefit. ${ }^{18}$ Patient education and self-management may have contributed to these positive outcomes. ${ }^{19-21}$ The physical exercise component of pulmonary rehabilitation also improves outcomes, ${ }^{22}$ although the weather has been reported as a major environmental barrier to improvement. ${ }^{23}$

Developed in conjunction with clinicians, Healthy Outlook is a service delivered by the Met Office directly to COPD patients utilising automated telephone calls; this has been in place since 2006 and ended in 2013 when the service was closed. Periods of higher risk of COPD exacerbations are forecast using a rule-based model, combining observed and forecast parameters including season, humidity, temperature, air quality and rates of influenzalike illness. The service provides COPD patients with a 10-day advance warning of forthcoming periods of higher risk and encourages them to act proactively to reduce their exposure to risk; in particular, the telephone call asks them to check for early symptoms of an exacerbation and ensure they have sufficient medication. ${ }^{12}$ Telephone calls were no more than fortnightly with typically four telephone calls in an average winter.

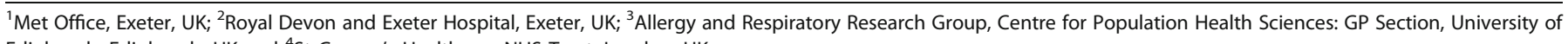
Edinburgh, Edinburgh, UK and ${ }^{4}$ St George's Healthcare NHS Trust, London, UK.

Correspondence: C Sarran (christophe.sarran@metoffice.gov.uk)

${ }^{5}$ Current address: Locum General Practitioner, London, UK.

Received 10 February 2014; revised 1 August 2014; accepted 31 August 2014 
The primary goal of the Healthy Outlook service is to reduce the severity and length of COPD exacerbations, hence improving the quality of life and life expectancy. Previous observational studies have reported a reduction in mortality and hospital admissions. ${ }^{24,25}$

A number of small studies have been carried out to assess the effectiveness of the Healthy Outlook service. A multicentre randomised controlled trial concluded that it may help reduce exacerbation rates, but the results were not statistically significant, possibly because of low (78) patient numbers. ${ }^{26}$ Another group, Bakerly et al., ${ }^{27}$ Salford Primary Care Trust, noted a reduction in visits to general practitioners and out-of-hours services; however, the number of home visits and the overall cost per patient increased. In Bradford and Airedale, Maheswaran et al. $^{28}$ did not find any significant change in hospital admissions associated with the service.

Although the primary goal of the Healthy Outlook service is not necessarily to reduce hospital admission rates, the Hospital Episodes Statistics database has been used to assess the effect of the Healthy Outlook service on hospital admission rates of all general practitioners that have used the automated service; this is the largest analysis of the effect of the Healthy Outlook service on hospital admissions and the results are presented here.

\section{MATERIALS AND METHODS}

Between 2007 and 2011, the Healthy Outlook service was provided to 31,941 COPD patients in 661 participating practices in England. A control practice with similar characteristics of deprivation, age profile and rurality was selected for each participating practice. The emergency hospital admission rates of COPD patients registered in participating practices were compared with those for control practices.

\section{Calculation of COPD admission rates}

The difference, $\Delta y_{\text {но, }}$ in admission rates per practice between the first year of use of the Healthy Outlook service and the previous year was calculated. This ensures that any change in hospital admission rate is based on rates that are normalised for the practices using the rate from the previous year as a baseline. This is compared with the difference, $\Delta y_{C_{1}}$ in admission rates for the same years for the matched control practice. The difference in differences, $\Delta y_{\mathrm{HO}}-\Delta y_{\mathrm{C}}$, was calculated and a paired $t$-test was used to compare the admission rates between the participating and control practices.

This analysis was extended to estimate the effect of the service on the admission rate for the individual participating patient. An enrolled patient is assumed to be fully participating such that their individual difference in admission rate may be regarded as the difference in admission rate of the practice adjusted for the participation rate within the practice. The $\Delta y_{\text {но }}-\Delta y_{C}$ difference was adjusted for patient participation rate by means of the linear regression of $\Delta y_{H O}-\Delta y_{C}$ against the participation rate. The coefficient of this regression provides an estimate of the effect of the Healthy Outlook service on the individual participating COPD patient

The numbers of hospital admissions for each practice and year were obtained from the Hospital Episode Statistics database: these consisted of (1) emergency admissions with a primary diagnosis of COPD (ICD-10 codes J40 to J44 (ref. 29)) and (2) emergency admissions wherein COPD was any one of the diagnosis codes, as the primary diagnosis or as co-morbid COPD (termed here as 'any diagnosis of COPD'). The years were determined from the start date of the Healthy Outlook service for each practice, defined as the date the first patient was enrolled: the year before the service is the 1-year period up to the start date, and the first year of the service is the 1 -year period from the start date.

A hospital admission rate was obtained by dividing the number of admissions by the number of COPD patients registered at the practice. The COPD 1 indicator reported by practices and available on the Quality and Outcomes framework database $\mathrm{e}^{30}$ is the ratio of the number (numerator) of patients on the practice's COPD register against the total number (denominator) of patients registered at the practice. The COPD 1 numerator was extracted from the Quality and Outcomes framework database and provides the number of COPD patients for each practice. The COPD 1 indicator is reported at the end of each financial year such that the number of COPD patients for the previous year is taken as that last reported before the start date, and the number of patients for the first year is that first reported after the start date (e.g., a start date of 1 December
2008 means that the number of COPD patients registered at the end of March 2008 is used for the previous year and that registered at the end of March 2009 is used for the first year).

Other factors (e.g., deprivation ${ }^{31}$ ) may influence the change in admission rates from year to year for any given practice. Therefore, we matched a control practice with similar characteristics to each of the 661 participating practices, by adapting the method developed by the Eastern Region Public Health Observatory. ${ }^{32-34}$ Each practice was characterised according to their Index of Multiple Deprivation (IMD), ${ }^{35}$ the age profile of their patients (i.e., the percentage of registered patients aged 65 years or over) and the rurality classification ${ }^{36}$ of their Middle Super-Output Area given by the Office for National Statistics.

These three parameters were used as percentiles such that the control practices were chosen by finding the lowest total percentile difference between the two groups, such that the nearest available neighbour in terms of these parameters was chosen with replacement for each participating practice. If $c_{\mathrm{IMD}}, c_{\mathrm{age}}$ and $c_{\mathrm{r}}$ were the percentiles for IMD, age and rurality, respectively, for participating practices, and similarly $C^{\prime}{ }_{I M D}, C^{\prime}$ age and $C_{r}^{\prime}$ for the control practices, matched control practices were found by minimising the total percentile difference $\sum\left(\left|c_{\text {IMD }}-c_{\text {IMD }}^{\prime}\right|+\left|c_{\text {age }}-c_{\text {age }}^{\prime}\right|+\left|c_{r}-c_{r}^{\prime}\right|\right)$.

Emergency hospital admission rates for heart failure (ICD-10 code I50) and myocardial infarction (ICD-10 codes I21 and I22) in the year before the start of the service were compared using paired $t$-tests, for participating, and control surgeries to ensure that the two groups were well matched.

\section{RESULTS}

The number of emergency hospital admissions from the Hospital Episode Statistics database and the number of COPD patients registered from the Quality and Outcomes framework database (Table 1) provide the admission rates for each participating and control practice before and after the start of the Healthy Outlook service. The mean patient participation rate in relation to the COPD patient population was $40.7 \%$ with $95 \%$ of practices, with a participation rate between 11 and $81 \%$. The results are summarised in Table 2 . Prediction intervals are provided because they are a measure of the scatter and distribution of the data.

Histograms of the characteristics for practices participating in Healthy Outlook and for all general practices in England are compared in Figure 1: the plots suggest that the distribution of

Table 1. Descriptive statistics of the data per practice: number of registered COPD patients in each practice, number of admissions with primary diagnosis and any diagnosis of COPD, number of Healthy Outlook patients and participation rate

\begin{tabular}{|c|c|c|}
\hline \multirow[t]{2}{*}{ Data } & \multicolumn{2}{|c|}{$\begin{array}{l}\text { Mean with } 95 \% \text { confidence interval } \\
\text { (95\% prediction interval in italics) }\end{array}$} \\
\hline & Healthy Outlook & Control \\
\hline $\begin{array}{l}\text { Registered COPD patients } \\
\text { previous year }\end{array}$ & $\begin{array}{l}119(113 \text { to } 124) \\
\quad(27 \text { to } 253)\end{array}$ & $\begin{array}{l}101 \text { (95 to } 106) \\
\quad(19 \text { to } 246)\end{array}$ \\
\hline $\begin{array}{l}\text { Registered COPD patients } \\
\text { start year }\end{array}$ & $\begin{array}{l}125 \text { (119 to } 131) \\
(29 \text { to } 272)\end{array}$ & $\begin{array}{l}105(100 \text { to } 111) \\
\quad(21 \text { to } 247)\end{array}$ \\
\hline $\begin{array}{l}\text { Primary diagnosis } \\
\text { admissions previous year }\end{array}$ & $\begin{array}{c}15.4 \text { (14.6 to } 16.3) \\
\text { (2 to 38) }\end{array}$ & $\begin{array}{c}14.1 \text { (13.2 to } 15.0) \\
\text { (2 to } 37)\end{array}$ \\
\hline $\begin{array}{l}\text { Primary diagnosis } \\
\text { admissions start year }\end{array}$ & $\begin{array}{c}15.2 \text { (14.3 to } 16.1) \\
\text { (1 to 38) }\end{array}$ & $\begin{array}{c}14.2 \text { (13.3 to } 15.2) \\
\text { (1 to 39) }\end{array}$ \\
\hline $\begin{array}{l}\text { Any diagnosis admissions } \\
\text { previous year }\end{array}$ & $\begin{array}{c}46.6 \text { (44.2 to } 49.0) \\
\text { (9 to 106) }\end{array}$ & $\begin{array}{c}41.0 \text { (38.6 to } 43.5) \\
\text { (6 to 102) }\end{array}$ \\
\hline $\begin{array}{l}\text { Any diagnosis admissions } \\
\text { start year }\end{array}$ & $\begin{array}{l}48.6 \text { (45.8 to } 51.3) \\
\text { (8 to } 114)\end{array}$ & $\begin{array}{c}43.3(40.6 \text { to } 46.0) \\
\text { (5 to } 110)\end{array}$ \\
\hline Number of Healthy & 48.3 (45.1 to 51.5 ) & Nil \\
\hline Outlook patients & (9 to 123 ) & \\
\hline $\begin{array}{l}\text { Healthy Outlook } \\
\text { participation rate (\%) }\end{array}$ & $\begin{array}{l}40.7 \text { (39.2 to } 42.3) \\
\text { (11 to } 81)\end{array}$ & Nil \\
\hline
\end{tabular}


Table 2. Admission rates and $t$-test results with primary diagnosis and any diagnosis of COPD

\begin{tabular}{|c|c|c|}
\hline \multirow[t]{2}{*}{ Results } & \multicolumn{2}{|c|}{$\begin{array}{l}\text { Mean with } 95 \% \text { confidence interval } \\
\text { (95\% prediction interval in italics) }\end{array}$} \\
\hline & Healthy Outlook & Control \\
\hline $\begin{array}{l}\text { Primary diagnosis } \\
\text { admissions rate previous } \\
\text { year (\%) }\end{array}$ & $\begin{array}{c}14.0 \text { (13.3 to } 14.7) \\
\text { (4 to } 27)\end{array}$ & $\begin{array}{l}15.2(14.4 \text { to } 15.9) \\
\quad(3 \text { to } 35)\end{array}$ \\
\hline $\begin{array}{l}\text { Primary diagnosis } \\
\text { admissions } \\
\text { rate start year (\%) }\end{array}$ & $\begin{array}{c}12.4 \text { (11.8 to } 13.0) \\
\text { (3 to } 26)\end{array}$ & $\begin{array}{l}14.4 \text { (13.6 to } 15.2) \\
\quad(2 \text { to } 33)\end{array}$ \\
\hline $\begin{array}{l}\text { Primary diagnosis relative } \\
\text { change } \Delta y_{\mathrm{HO}}, \Delta y_{C}(\%)\end{array}$ & $\begin{array}{c}-1.5(-2.2 \text { to }-0.8) \\
(-16 \text { to } 9)\end{array}$ & $\begin{array}{l}-0.8(-1.5 \text { to } 0.0) \\
\quad(-15 \text { to } 14)\end{array}$ \\
\hline Primary diagnosis & -0.8 & $(-1.8$ to 0.2$)$ \\
\hline$\Delta y_{H O}-\Delta y_{C}$ difference (\%) & & $(-19$ to 17$)$ \\
\hline $\begin{array}{l}\text { Any diagnosis admissions } \\
\text { rate previous year (\%) }\end{array}$ & $\begin{array}{l}41.7 \text { (40.2 to } 43.2) \\
\text { (18 to } 75)\end{array}$ & $\begin{array}{l}42.9 \text { (41.3 to } 44.6) \\
\quad(18 \text { to } 81)\end{array}$ \\
\hline $\begin{array}{l}\text { Any diagnosis admissions } \\
\text { rate start year (\%) }\end{array}$ & $\begin{array}{c}39.7 \text { (38.3 to } 41.1) \\
(12 \text { to } 70)\end{array}$ & $\begin{array}{l}43.2(41.5 \text { to } 45.0) \\
\quad(12 \text { to } 87)\end{array}$ \\
\hline $\begin{array}{l}\text { Any diagnosis relative } \\
\text { change } \Delta y_{H O}, \Delta y_{C}(\%)\end{array}$ & $\begin{array}{c}-2.0(-3.5 \text { to }-0.4) \\
(-37 \text { to } 22)\end{array}$ & $\begin{array}{c}+0.3(-1.3 \text { to } 1.9) \\
\quad(-34 \text { to } 30)\end{array}$ \\
\hline Any diagnosis & -2.3 & $(-4.2$ to -0.4$)$ \\
\hline$\Delta y_{\text {HO }}-\Delta y_{C}$ difference (\%) & & $(-43$ to 33$)$ \\
\hline
\end{tabular}

Abbreviations: C, Control; COPD, chronic obstructive pulmonary disease; $\mathrm{HO}$, Healthy Outlook. participating practices does not differ much from that of an average English practice. From matching a control practice to each participating practice, the mean percentile difference between matched practices was $2.3 \%$ with $95 \%$ of matches with a percentile difference within $0.8-4.3 \%$. Figure 2 shows a comparison of the IMD and age between participating and control practices, the tight clustering of the points along the diagonal suggesting a good match. Paired $t$-tests of the admission rates for heart failure and myocardial infarction in the year before the start of the service resulted in a mean difference between the two groups of $-0.01 \%$ o (95\% confidence interval $(\mathrm{Cl})=-0.08$ to $0.07 \%$; $P=0.9)$ for heart failure and $-0.02 \%$ o (95\% Cl= -0.09 to $0.05 \%$; $P=0.6)$ for myocardial infarction. This suggests that the participating practices are well matched to their controls as there were no differences in emergency hospital admission rates for these two outcomes.

For admissions with a primary diagnosis of COPD, the mean absolute change in admission rate for participating practices between the start year and the previous year was $-1.5 \%(95 \%$ $\mathrm{Cl}=-2.2$ to $-0.8 \%$ ). For the control practices this figure was $-0.8 \%$ ( $95 \% \mathrm{Cl}=-1.5$ to $0.0 \%)$. The difference between participating and control practices was $-0.8 \%(95 \% \mathrm{Cl}=-1.8$ to $0.2 \% ; P=0.13)$.

For admissions with any diagnosis of COPD, there was a mean absolute reduction in admission rates for participating practices of $2.0 \%(95 \% \mathrm{Cl}=3.5$ to $0.4 \%)$ and, a corresponding increase of $0.3 \%(95 \% \mathrm{Cl}=-1.3$ to $1.9 \%)$ in the control practices. The paired $t$-test yielded a difference, $\Delta y_{H O}-\Delta y_{C}$ of $-2.3 \%(95 \% \mathrm{Cl}=-4.2$ to $-0.4 \% ; P=0.02$ ).
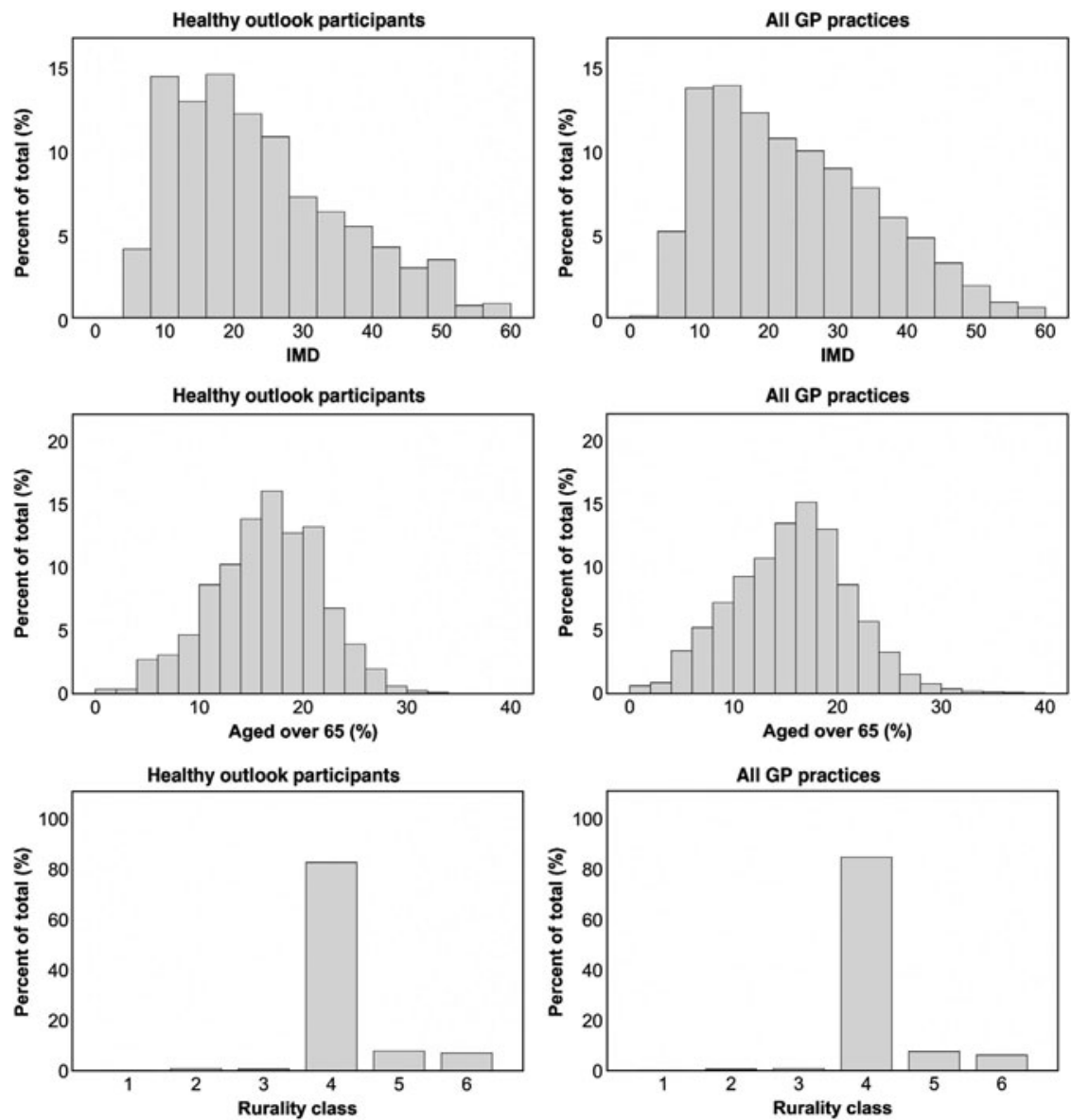

Figure 1. Distributions of Index of Multiple Deprivation (IMD), percentage of patients aged over 65 and rurality class for practices participating in Healthy Outlook and for all practices in England. (Rurality classes are: 1-urban >10 K-sparse; 2-town and fringe-sparse; 3-village, hamlet and isolated dwellings-sparse; 4-urban >10 K-less sparse; 5-town and fringe-less sparse; 6-village, hamlet and isolated dwellings-less sparse.) 
For the regression of the $\Delta y_{H O}-\Delta y_{C}$ difference against participation rate, the regression coefficient is $-0.023(95 \%$ $\mathrm{Cl}=-0.045$ to $-0.002 ; P=0.04$ ) for admissions with a primary diagnosis of COPD. This equates to an estimated difference in admission rate of $-2.3 \%$ for the participating COPD patient.
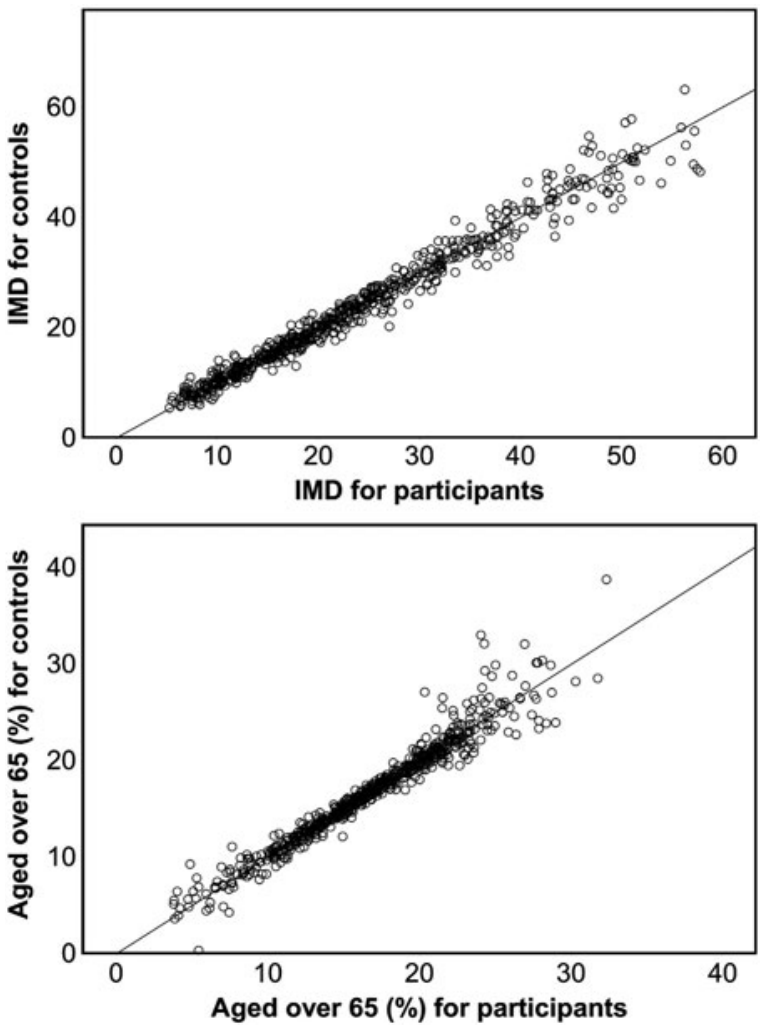

Figure 2. Index of Multiple Deprivation (IMD) and percentage of registered patients aged over 65 of matched control practices against participating practices. An equivalent plot for rurality class is not shown because its categorical nature makes the plot unhelpful.
For admissions with any diagnosis of COPD (i.e., when COPD was the primary diagnosis or a co-morbid condition), the regression coefficient was $-0.07(95 \% \mathrm{Cl}=-0.11$ to -0.03 ; $P=0.001)$. This equates to an estimated difference in admission rate of $-7 \%$ for the participating patient.

\section{DISCUSSION}

\section{Main findings}

In the year after recruitment, the difference between participating and control practices was $-0.8 \%$ for admissions with a primary diagnosis of COPD. Therefore, for an average practice with a primary diagnosis admission rate of $15 \%$ (see Table 2), the effect of the Healthy Outlook service was a 5\% drop in admissions with a primary diagnosis of COPD (i.e., $0.8 \%$ is $5 \%$ of $15 \%$ ). Furthermore, the difference between practices equates to a difference in admission rate of $-2.3 \%$ for participating patients. Taking the primary diagnosis mean admission rate of $14 \%$ (see Table 2 ) before the start of the service for participating practices, the admission rate difference is equivalent to an average reduction in primary diagnosis admissions of $16 \%(95 \% \mathrm{Cl}=1$ to $32 \%$; c.f. Figure 3$)$. This average reduction appears significant, whereas the difference of $-0.8 \%$ between participating and control practices was not, because a further assumption was made that no participation means no effect, thus constraining the result to a narrower interval.

The difference was $-2.3 \%$ for admissions with any diagnosis of COPD. Therefore, for an average practice with an admission rate of $43 \%$ for any diagnosis (see Table 2), the effect of the service was a $5 \%$ drop in admissions with any diagnosis of COPD (i.e., $2.3 \%$ is $5 \%$ of $43 \%$ ). Furthermore, the difference between practices equates to a difference in admission rate of $-7 \%$ for participating patients. Taking the mean admission rate of $42 \%$ for any diagnosis (see Table 2) before the start of the service for participating practices, the admission rate difference was found to be equivalent to an average reduction in any diagnosis admissions of $16 \%(95 \% \mathrm{Cl}=6$ to $26 \%)$.

Strengths and limitations of this study

This study is the first to examine the impact of the Healthy Outlook service in England by examining the admission rates for
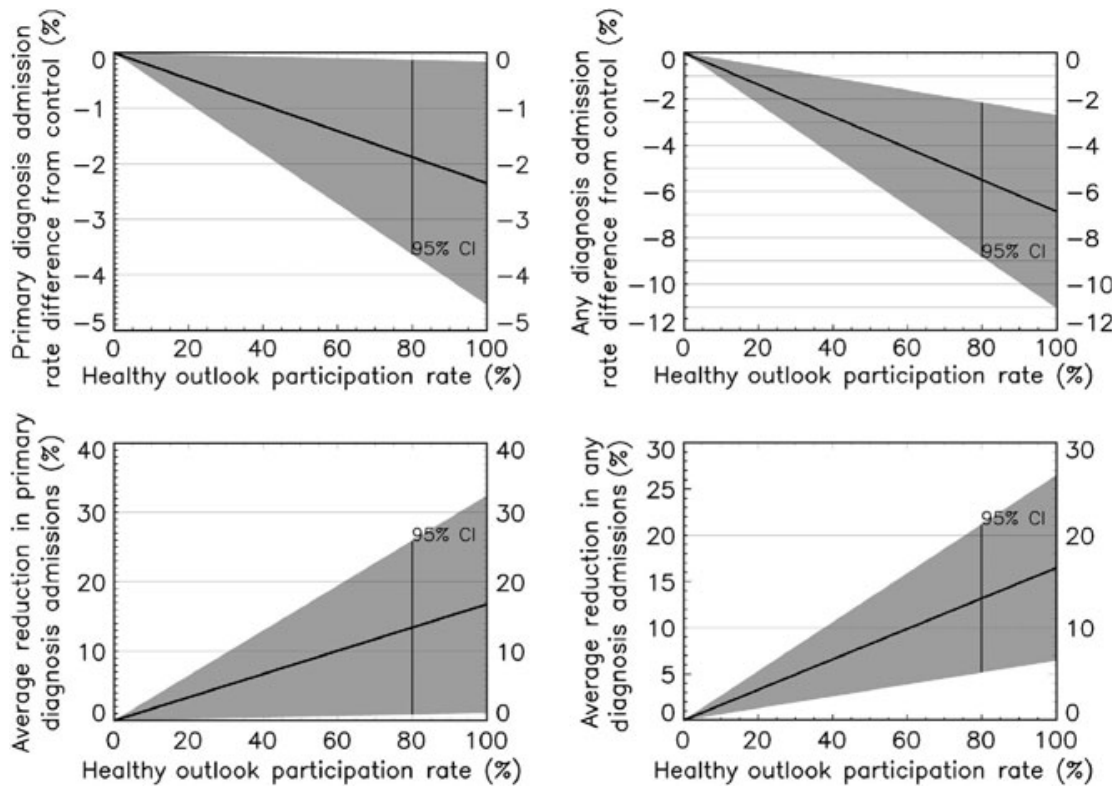

Figure 3. Regression lines with $95 \%$ confidence intervals (Cls) for the linear regression of the $\Delta y_{\mathrm{HO}}-\Delta y_{\mathrm{C}}$ difference against Healthy Outlook participation rate for primary and any (secondary) diagnosis of COPD, and the equivalent regression lines for average reductions in admissions assuming a mean admission rate of 14 and $42 \%$ for primary and any diagnosis of COPD, respectively. 
all of the 661 participating practices where the participating COPD patients were registered. Not all COPD patients registered at a participating practice received the Healthy Outlook service. Therefore, the effect of the Healthy Outlook service on the admission rates is expected to be dependent on the patient participation rate within each practice. Admission rates per practice are also dependent on the severity of COPD of the patients registered in the practice as well as on other efforts made by the practice to address COPD admissions. Furthermore, the risk to COPD patients and therefore the risk of an emergency hospital admission will vary from year to year because of factors such as changes in levels of circulating viruses. While participating practices were clustered by commissioning organisation, usually Primary Care Trusts, they present a wide geographical distribution illustrated in Figure 4, such that it is unlikely that participating practices were climatically biased compared with the controls.

A limitation of the Eastern Region Public Health Observatory method for matching practices is that it does not take into account factors that might be linked to the take-up of the service, such as practices with a larger number of registered patients being more engaged in offering the service to patients. This would account for the significant difference in the number of COPD patients registered in participating and control practices, with 18 more patients in participating practices $(95 \% \mathrm{Cl}=11$ to 25 ; $P<0.001$ ). The number of patients per practice could have been an additional matching criterion. Because it is already used as the denominator to measure the admission rate as outcome, the number of patients per practice was not used as a criterion for matching.

Interpretation of findings in relation to previously published work A cohort study was carried out by Steventon et al. ${ }^{37}$ for 1,413 COPD patients matched to controls and enrolled in the Healthy Outlook service in 102 participating practices: they concluded that Healthy Outlook did not reduce admission rates but found lower mortality rates. A significant difference in their approach is in not

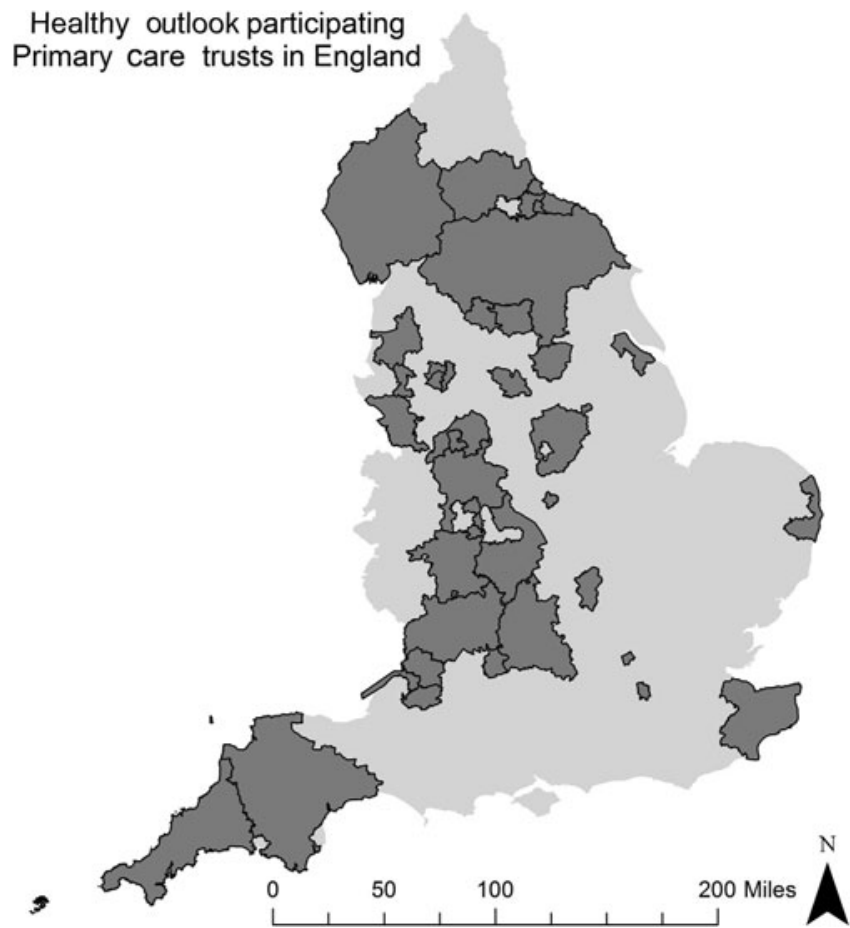

Figure 4. Locations of the Primary Care Trusts (PCT) in England with practices participating in the Healthy Outlook service. having included unspecified and chronic bronchitis in the counts of COPD hospital admissions. A possible explanation is that mildto-moderate COPD sufferers avoid hospitals following a telephone alert, whereas more severe sufferers will need emergency care in any case and despite the alert.

Although anticipatory care interventions are often well received, ${ }^{38}$ COPD disease management can yield significant direct health-care costs ${ }^{39}$ including the use of telemedicine. ${ }^{40}$ Although we have demonstrated a small but statistically significant reduction in hospital admissions for participating practices, it is unclear how the cost-benefit of the Healthy Outlook can be quantified. Economic evaluation depends on the analytic approach adopted. ${ }^{41}$ Modelling the natural history of COPD linked with health economics may provide a more precise cost-benefit assessment. ${ }^{42-44}$

Implications for future research, policy and practice

We found a $5 \%$ reduction in primary COPD diagnosis hospital admission rates when comparing participating and control practices in the year following adoption of the Healthy Outlook service. While the difference was not statistically significant, this may be explained by the range of uptake of the service within the participating practices (11 and 81\%). However, and possibly more importantly, we have demonstrated a small, statistically significant net reduction in hospital admission rates in patients with any primary or co-morbid diagnosis of COPD. The importance of this finding emphasises the contribution of co-morbid COPD on overall hospital admissions, which has a knock-on effect when planning health-care provision.

Furthermore, when allowing for differences in participation rates (or 'exposure' to the service), changes in admission rates for those with a primary or co-morbid diagnosis of COPD are statistically significant and equivalent to a $16 \%$ drop in admissions.

\section{Conclusions}

We have demonstrated that participation in the Healthy Outlook service of the Met Office reduces hospital admission rates for patients coded on discharge with a primary or co-morbid diagnosis of COPD. This has major implications for patient wellbeing as well as for NHS resources.

\section{ACKNOWLEDGEMENTS}

The authors thank the members of the Met Office's COPD Advisory Group for designing and reviewing this evaluation and the Met Office for funding it.

\section{CONTRIBUTIONS}

All authors together designed the study and reviewed the results; Christophe Sarran carried out the analysis; the manuscript was written by MLL and CS with contributions from $\mathrm{DH}$; all authors reviewed drafts of the manuscript.

\section{COMPETING INTERESTS}

This evaluation was funded and conducted by the Met Office. Professor Halpin chaired the Met Office's COPD Advisory Group. MLL has accepted sponsorship from GlaxoSmithKline (GSK), AstraZeneca (AZ), Boehringer Ingelheim (BI), Chiesi, Merck Sharpe and Dohme (MSD), Merck, Altana Pharma, Novartis, Meda Pharmaceuticals, 3M Pharmaceuticals, Napp Pharmaceuticals, TEVA and Schering Plough for attending conferences. He has accepted lecture fees from BI, GSK, AZ, Chiesi, TEVA and Alk-Abello. He has been on advisory boards or provided consultancy for GSK, Schering Plough, MSD, Chiesi, Altana Pharma, Ranbaxy, AZ, Clement Clarke International, National Services for Health Improvement (NSHI) and Novartis. He has had research grants from Bl, Pfizer and GSK. He is a member of The Aerosol Drug Management Improvement Team (ADMIT), which is supported by an unrestricted educational grant from Consorzio Ferrara Ricerche. Mark L. Levy is the Editor Emeritus of the PCRJ, but 
was not involved in the editorial review of, nor the decision to publish, this article. The remaining authors declare no conflict of interest.

\section{FUNDING}

Met Office.

\section{REFERENCES}

1 Lopez AD, Murray CC. The global burden of disease, 1990-2020. Nat Med 1998; 4 1241-1243.

2 Pauwels RA, Rabe KF. Burden and clinical features of chronic obstructive pulmonary disease (COPD). Lancet 2004; 364: 613-620.

3 Department of Health. An Outcomes Strategy for COPD and Asthma: NHS Companion Document. NHS: London, UK, 2012.

4 Roberts CM, Lowe D, Bucknall CE, Ryland I, Kelly Y, Pearson MG. Clinical audit indicators of outcome following admission to hospital with acute exacerbation of chronic obstructive pulmonary disease. Thorax 2002; 57: 137-141.

5 Wouters EFM. Economic analysis of the confronting COPD survey: and overview of results. Respir Med 2003; 97: S3-S14.

6 Wouters EFM. Management of severe COPD. Lancet 2004; 364: 883-895.

7 Dennekamp M, Prescott GJ, Seaton A. The health effects of weather and particulate air pollution on people with COPD or chronic asthma. Thorax 2001 56 (Suppl III): iii16.

8 Bhowmik A, Seemungal TAR, Donaldson GC, Wedzicha JA. Effects of exacerbations and seasonality on exhaled nitric oxide in COPD. Eur Respir J 2005; 26 1009-1015.

9 Ferrari U, Exner T, Wanka ER, Bergemann C, Meyer-Arnek J, Hildenbrand B et al. Influence of air pressure, humidity, solar radiation, temperature, and wind speed on ambulatory visits due to chronic obstructive pulmonary disease in Bavaria, Germany. Int J Biometeorol 2012; 56: 137-143.

10 Koskela HO, Koskela AK, Tukiainen HO. Bronchoconstriction due to cold weather in COPD-The roles of direct airway effects and cutaneous reflex mechanisms. Chest 1996; 110: 632-636.

11 Hondula DM, Davis RE, Knight DB, Sitka LJ, Enfield K, Gawtry SB et al. A respiratory alert model for the Shenandoah Valley, Virginia, USA. Int J Biometeorol 2013; 57 91-105.

12 Halpin DMG, Laing-Morton T, Spedding S, Levy ML, Coyle P, Lewis J et al. A randomised controlled trial of the effect of automated interactive calling combined with a health risk forecast on frequency and severity of exacerbations of COPD assessed clinically and using EXACT PRO. Prim Care Respir J 2011; 20: 324-331.

13 Dale J, Connor S, Tolley K. An evaluation of the west Surrey telemedicine monitoring project. J Telemed Telecare 2003; 9(Suppl 1): S39-S41.

14 Bird S, Noronha M, Sinnott H. An integrated care facilitation model improves quality of life and reduces use of hospital resources by patients with chronic obstructive pulmonary disease and chronic heart failure. Aust J Prim Health 2010; 16: 326-333.

15 Steuten L, Vrijhoef B, van Merode F, Wesseling GJ, Spreeuwenberg C. Evaluation of a regional disease management programme for patients with asthma or chronic obstructive pulmonary disease. Int J Qual Health Care 2006; 18: 429-436.

16 Lemmens KMM, Nieboer AP, Rutten-van Molken MPMH, van Schayck CP, Asin JD, Dirven JAM et al. Application of a theoretical model to evaluate COPD disease management. BMC Health Serv Res 2010; 10: 81.

17 Steventon A, Bardsley M, Billings J, Dixon J, Doll H, Hirani S et al. Effect of telehealth on use of secondary care and mortality: findings from the Whole System Demonstrator cluster randomised trial. BMJ 2012; 344: e3874.

18 Pinnock H, Hanley J, McCloughan L, Todd A, Krishan A, Lewis S et al. Effectiveness of telemonitoring integrated into existing clinical services on hospital admission for exacerbation of chronic obstructive pulmonary disease: researcher blind, multicentre, randomised controlled trial. BMJ 2013; 347: f6070.

19 Bourbeau J. Disease-specific self-management programs in patients with advanced chronic pulmonary disease - A comprehensive and critical evaluation Dis Manag Health Out 2003; 11: 311-319.

20 Worth $\mathrm{H}$, Dhein Y. Does patient education modify behaviour in the management of COPD?. Patient Educ Couns 2004; 52: 267-270.

21 Cummings $E$, Turner $P$. Patient self-management and chronic illness: evaluating outcomes and impacts of information technology. Stud Health Technol Inform 2009; 143: 229-234.

22 de Blok BMJ, de Greef MHG, ten Hacken NHT, Sprenger SR, Postema K, Wempe JB. The effects of a lifestyle physical activity counselling program with feedback of a pedometer during pulmonary rehabilitation in patients with COPD: a pilot study. Patient Educ Couns 2006; 61: 48-55.
23 O'Shea SD, Taylor NF, Paratz JD. But watch out for the weather: factors affecting adherence to progressive resistance exercise for persons with COPD. J Cardiopulm Rehabil Prev 2007; 27: 166-174.

24 Met Office. . Reducing Hospital Admissions During Winter. Case Study: Healthy Outlook-NHS Bath and North East Somerset. Met Office: Exeter, UK, 2010.

25 Met Office. Reducing Hospital Admissions During Winter. Case Study: Healthy Outlook-Moray Community Health Partnership. Met Office: Exeter, UK, 2010.

26 Halpin D, Laing-Morton T, Levy M, Marno P. Effect of an innovative automated interactive health forecast alert system on rate of exacerbations of COPD. Thorax 2009; 64: A115.

27 Bakerly ND, Thompson A, Roberts JA. Effect of telephone weather alert system on emergency COPD admissions and healthcare utilisation in patients with mild to moderate airflow obstruction. Thorax 2009; 64: A114-A115.

28 Maheswaran R, Pearson T, Hoysal N, Campbell MJ. Evaluation of the impact of a health forecast alert service on admissions for chronic obstructive pulmonary disease in Bradford and Airedale. J Public Health 2009; 32: 97-102.

29 WHO. ICD-10 Version: 2010. World Health Organization: Geneva, Switzerland 2010.

30 Jamie G. QOF Database - All of the Data for all Years (2005-11). Gavin Jamie: Swindon, UK, 2011.

31 McAllister DA, Morling JR, Fischbacher CM, MacNee W, Wild SH. Socioeconomic deprivation increases the effect of winter on admissions to hospital with COPD: retrospective analysis of 10 years of national hospitalisation data. Prim Care Respir J 2013; 22: 296-299.

32 Walford H, Ramsay L. COPD Prevalence Modelling Briefing Document. ERPHO: Cambridge, UK, 2011.

33 Nacul L, Soljak M, Samarasundera E, Hopkinson NS, Lacerda E, Indulkar T et al. COPD in England: a comparison of expected, model-based prevalence and observed prevalence from general practice data. J Public Health 2010; 33: 108-116.

34 Nacul LC, Soljak M, Meade T. Model for estimating the population prevalence of chronic obstructive pulmonary disease: cross sectional data from the Health Survey for England. Popul Health Metr 2007; 5: 8.

35 McLennan D, Barnes H, Noble M, Davies J, Garratt E, Dibben C. The English Indices of Deprivation 2010. Department for Communities and Local Government: London, UK, 2011

36 Bibby P, Shepherd J. Developing a New Classification of Urban and Rural Areas for Policy Purposes - the Methodology. Department for Environment, Food and Rural Affairs: London, UK, 2005.

37 Steventon A, Bardsley M, Mays N. Effect of a telephonic alert system (Healthy Outlook) for patients with chronic obstructive pulmonary disease: a cohort study with matched controls. J Public Health (Oxf) 2014; e-pub ahead of print 10 July 2014; doi:10.1093/pubmed/fdu042.

38 Cleland J, Moffat M, Small I. A qualitative study of stakeholder views of a community-based anticipatory care service for patients with COPD. Prim Care Respir J 2012; 21: 255-260.

39 de Bruin SR, Heijink R, Lemmens LC, Struijs JN, Baan CA. Impact of disease management programs on healthcare expenditure for patients with diabetes, depression, heart failure or chronic obstructive pulmonary disease: a systematic review of the literature. Health Policy 2011; 101: 105-121.

40 Haesum LKE, Soerensen N, Dinesen B, Nielsen C, Grann O, Hejlesen O et al. Cost-utility analysis of a telerehabilitation program: a case study of COPD patients. Telemed E-Health 2012; 18: 688-692.

41 Hoogendoorn M, Al M, Rutten-van Molken MP. Discrepancy between analytic approaches in the clinical and economic evaluation of the same trial: experience in COPD. Value Health 2010; 13: A324.

42 Borg S, Ericsson A, Wedzicha J, Gulsvik A, Lundback B, Donaldson GC et al. A computer simulation model of the natural history and economic impact of chronic obstructive pulmonary disease. Value Health 2004; 7: 153-167.

43 Menn P, Holle R. Markov model for health-economic evaluations of COPD in Germany. Value Health 2009; 12: A303.

44 Menn P, Leidl R, Holle R. A lifetime Markov model for the economic evaluation of chronic obstructive pulmonary disease. Pharmacoeconomics 2012; 30: 825-840.

(c) (i) (2) This work is licensed under a Creative Commons Attribution(cc) NonCommercial-ShareAlike 4.0 International License. The images or other third party material in this article are included in the article's Creative Commons license, unless indicated otherwise in the credit line; if the material is not included under the Creative Commons license, users will need to obtain permission from the license holder to reproduce the material. To view a copy of this license, visit http:// creativecommons.org/licenses/by-nc-sa/4.0/ 